\title{
Review on Nonlinear Behavior Assessment of Reinforced Concrete Frames by Carbon Fiber Reinforced Polymers under Blast Loading
}

\author{
Mahdi Kolbadi* \\ KN Toosi University of Technology, Iran
}

*Corresponding author: Mahdi Kolbadi, KN Toosi University of Technology, Iran.

\section{Mini Review}

This review focuses on the numerical nonlinear analysis of blast pressure wave propagation on CFRP reinforced buildings. The frequency and severity of missile attacks and terrorist operations have led to the need for building strengthened structures against these dangers. The implementing of extreme and immediate explosive energy imposed to buildings needs special requirements. Also, the CFRP reinforced structures shows their ability in facing to various types of dynamic loads such as earthquakes, winds and waves. Their ability to respond to such intense loads is evaluated in this research. Explosion is a very fast release of energy in the form of light, heat, sound and shock wave. The shock wave consists of a very dense air that moves quickly from the center of explosion outward with ultrasonic velocity. By the expansion of the shock wave, the value of pressure decreases rapidly (proportional to distance, the third factor) and reflects after reaching a rigid surface, and its amount may increase up to thirteen times. The magnitude of the reflection coefficient is in close proximity of the explosive and the angle of the hitting wave. Pressure also decreases exponentially. In loading of an explosive, the loading time is very short, and it is usually expressed in terms of milliseconds. These days, due to the unpleasant spread of the threat imposed to human life by explosion, the analysis and designating of important structures such as military, governmental and fundamental, and utilities against these loads are not anymore, a costly conservatism but an inevitable necessity. Regarding explosive analysis and designing, due to the nature of these charges and applications of the building and also observing economic issues, different levels of performance for the structure under the explosive load are considered. On the other hand, using modern approaches and efficient materials the structure can be reinforced [1].
Structure of the buildings can be effective in minimizing or reducing damage, in terms of behavior, against the effects of explosions. Reinforced concrete buildings can be better in large explosions, because they have a massive capacity to absorb more energy than steel buildings; other advantage of concrete is that it can also resist alone against compressive loads. On the other hand, the strain is tolerated by the bars, while in steel buildings; steel has the same capacity for pressure and tension [2]. The explosion wave results from the rapid rise in air pressure from the atmospheric point to the peak explosion pressure, which results in a rapid reduction in the atmospheric pressure of the substrate and ending with a gradual increase in atmospheric pressure. Therefore, the explosive wave has two phases. The rapid rise in pressure that results in an atmospheric increase is called positive phase or pressure phase and a decrease in atmospheric pressure that leads to a return to the atmospheric state is called negative phase or suction phase. At a certain distance from the site of the explosion, through time, the pressure of that place suddenly rises to reach its peak. Then, the pressure drops too slowly and goes down to the normal pressure and even lower [3]. The massive loads imposed to the materials for a short period of time do not fall under the category of the static and dynamic loadings. Due to the impossibility of gaining comprehensive knowledge of the explosion, in many cases, computer-based solutions are wellsuited for precise simulation. Knowledge of these cases is useful in analyzes and studies performed in this field [4]. In order to increase the strength of the structure against the explosion-induced loads, there are some commonly applied solutions, among which the most important are the use of local reinforcement such as steel covers and concrete covers for structural sections, as well as adding new 
structural systems such as a composite cutting steel wall. One of the disadvantages of such methods is that, it imposes significant gravity loads on the structure and ultimately on the foundation, and on the other hand, it requires a lot of time to install, thus it will not be financially favorable. An effective and economical approach to this goal is applying CFRPs to strengthen parts. CFRP composites have been used for about 50 years in structural engineering in the fields of fabrication, retrofit, reinforcement, restoration and refurbishment of existing structures. Over the last decade, a significant growth has been observed in the use of CFRP materials, which are an advanced form of composites. CFRP materials are composite materials which include highly resistant fibers that are put in a polymeric area [5].

Crawford et al. [1] studied the columns reinforced by CFRP sheets. In this experimental study, they studied the effect of reinforcing method of concrete columns on CFRP sheets. In 2009, Shie et al. [6] reviewed the pressure-shock diagram and predicted the damage rate of concrete columns under explosive loading and they presented their proposed method for predicting damages. Zhou et al. [7] has also studied the behavior of steel and concrete structures with different shapes and conditions under the influence of explosive loading. By comparing concrete and steel structures under explosion, they found that the performance of concrete structures is better. Also, in the case of the effect of the shape of structures, the structures that have lower perpendicular surfaces to the explosion, the performance of spherical structures is better than cubic structures. Astari et al. [8] studied the behavior of reinforced concrete columns under axial and transverse burst loads. He has introduced a model with single degree of freedom which is developed to examine the behavior of explosive-reinforced concrete pillars under explosion. According to the results, the magnitude of the axial load on the behavior of the reinforced concrete column under the explosion is so important that even if the axial load is half of the critical axial load of the column, it reduces its capacity against the side load of the explosion. In 2008, Arlree et al. [9] tried to simulate the columns of concrete numerically and examined the rate of damage and reduction of load capacity of the column under the explosion load. In this study, a numerical method was proposed to simulate the behavior of concrete artillery columns under the close explosion field and the remaining cargo capacity was estimated. Using ABAQUS software, they showed that among the changed parameters of the column, thickness, the radius of explosion charge and the ratio of the distance to this radius had the most important effects; the height, width and compressive strength of the concrete in the column had less effect on the Explosive response. Also, by providing an empirical formula, they predicted the amount of damage inflicted on concrete.

In 2010, Li et al. [10] carried out a numerical study on crushing of the concrete columns under the explosion load. In this study, a three-dimensional model was simulated and validated in comparison with laboratory samples. With a strong simulation, they dealt with various parameters of the column under the explosion and they observed that the amount of crushing of the concrete depends on the distance of the explosion, the strength of the concrete column and the boundary conditions. Although the depth of the column and the type of rearmament also has a significant impact on the rate of destruction, by increasing the depth of the column and the reinforcement, destruction rate decreases. Ghani et al. [11] have studied the behavior of concrete slabs reinforced with polymeric composite under explosive loading and used CONWEP software to calculate explosion loading parameters. In all conducted laboratory and numerical studies, reinforcement of concrete slabs with FRP sheets has led to increased load capacity, reduced sample deformation after the explosion and improved performance of the reinforced sample.

\section{Acknowledgment}

None.

\section{Conflict of Interest}

No conflict of interest.

\section{References}

1. Crawford JE, Malvas LJ, Wesevich JW, Valancius J, Reynolds AD (1997) Retrofit of reinforced concrete structures to resist blast effects. ACI Structural Journal 94(4): 371-377.

2. Unified Facilities Criteria (2008) Structures to resist the effects of accidental explosions, UFC 3-340-02, Department of Defense, US army corps of engineers, Naval facilities engineering command, Air force civil engineer support agency, USA.

3. US Department of Defense (2008) DoD 6055.09-STD. DoD ammunition and explosives safety standard, USA.

4. Kravfsourd W, Zhang D, Lu F, Wang SC, Tang F (2012) Experimental study on scaling the explosion resistance of a one-way square reinforced concrete slab under a close-in blast loading. International Journal of Impact Engineering 49: 158-164.

5. Louchinie G, Hetherington J, Rose T (1999) Response to blast loading of concrete wall panels with openings. Journal of Structural Engineering 125(12): 1448-1450.

6. Shie PF, Lu B (2009) Blast resistance capacity of reinforced concrete slabs. Journal of Structural Engineering 135(6): 708-716.

7. Zhou X, Kuznetsov V, Hao H, Waschl J (2008) Numerical prediction of concrete slab response to blast loading. International Journal of Impact Engineering 35(10): 1186-1200.

8. Astari, Tolba A, Contestabile E (2007) Blast loading response of reinforced concrete panels reinforced with externally bonded GFRP laminates. Composites Part B. Engineering 38(5-6): 535-546.

9. Arlree, Anteby I, Gal E, Kivity Y, Nizri E, et al. (2008) Full-scale field tests of concrete slabs subjected to blast loads. International Journal of Impact Engineering 35(3): 184-198.

10. Li Y, Shie ZX, Hao H (2010) A new method for progressive collapse analysis of RC frames under blast loading. Engineering Structures 32(6): 1691-1703.

11. Ghani R, Thambiratnam DP, Perera NJ, Kosse V (2011) Blast and residual capacity analysis of reinforced concrete framed buildings. Engineering Structures 33: 3483-3495. 